\title{
A METAHEURISTIC ALGORITHM FOR SOLVING SIMULTANEOUS SCHEDULING PROBLEMS
}

\author{
PRAKASH BABU KANAKAVALLI ${ }^{1}$, VIJAYA BABU VOMMI ${ }^{2}$ \\ ${ }^{1}$ Assistant Professor, Department of Mechanical Engineering, V.R. Siddhartha Engineering College, A.P, India \\ ${ }^{2}$ Professor, Department of Mechanical Engineering, A.U College of Engineering, Andhra University, A.P, India
}

\begin{abstract}
In facing the challenges evolving in the day to day global competition, Flexible manufacturing systems has become the right choice for the manufacturers. But efficient scheduling is needed for its successful implementation. In its scheduling not only sequencing of jobs on machines but also the routing of the jobs through the system is important. Not only scheduling of machines but also others resources available in the system like Automated Guided Vehicle (AGV) and Automated Storage/Retrieval System (AS/RS) must also be considered during this process. In the present work a procedure for simultaneous scheduling of machines and AGVs is used and this procedure is integrated with differential evolution metaheuristic for scheduling both the machines and AGVs simultaneously in order to minimize the makespan. The performance of the proposed metaheuristic is evaluated by considering 82 benchmark problems consisting of different job sets and layout configurations. Finally the obtained makespans are compared with the previously proposed algorithms available in the literature.
\end{abstract}

KEYWORDS: FMS, Makespan, Differential Evolution and Automated Guided Vehicle

Received: Jun 08, 2020; Accepted: Jun 28, 2020; Published: Sep 18, 2020; Paper Id.: IJMPERDJUN20201319

\section{INTRODUCTION}

FMS is a highly automated and sophisticated system in the field of manufacturing to achieve high flexibility and productivity in mid-variety and mid-range of products (Akturk, et al. 1996) [1]. The great demand for goods needs new way to enhance productivity with existing manufacturing system and available resources (Sabuncuoglu, et al. 1992) [2]. FMS has emerged as a viable alternative to the conventional manufacturing system and showed benefits in cost reduction, enhanced utilizations, reduced work-in-process levels, etc. The problems encountered in the life cycle of a FMS are classified in to design, planning, scheduling and control (Karabtik, et al. (1993) [3]. The task of scheduling and controlling problems plays an important role during operation owing to the dynamic nature of the FMS such as flexible parts, tools, AGV routings (Kusiaka.1985) [4] and AS/RS storage assignments (El-Maraghy, et al. 1992) [5]. Scheduling of machines in FMS is made through sequencing of jobs on machines, and routing of jobs through the system (Orhan, \& Lee, et al. 1989) [6]. Other resources in the system, (e.g. material-handling devices like AGVs and AS/RS) need to be considered. To have flexible and efficient production, automated guided vehicle systems (AGVS) and the material-handling system (MHS) are being employed (Blazewicz, et al. (1991) [7]. The AGVs effectiveness depends on several factors. Function of a well-designed vehicle management are: Dispatching the process of selecting and assigning tasks to AGV; Routing the process of selecting specific paths by AGVs; and Scheduling - the process of determining the arrival and departure dates. The demand for goods 
enhances pressure on manufacturing systems seeking ways to increase productivity with available resources.

\section{LITERATURE REVIEW}

\section{Simultaneous Scheduling in FMS}

A numerical example for simultaneous scheduling of machines and AGVs in FMS environment is proposed by Bilge and Ulusoy (1995) [8].The authors adopted sliding time window (STW) method. Ulusoy et al. (1997) [9] has utilized genetic algorithms for solving the simultaneous scheduling of machines and material handling problems in an FMS environment so as to minimize the makespan. A hybrid GA was proposed by Abdelmaguid et al. (2004) [10] to minimize the makespan for the problem of simultaneous scheduling of machines and AGVs in FMS .The algorithm is applied to a set of 82 test problems, which was constructed by other researchers, and the comparison of the results indicates the superior performance with the developed coding. Reddy and Rao (2006) [11] studied the simultaneous scheduling problem with makespan, mean flow time and mean tardiness as an criterion. The proposed hybrid GA for FMS scheduling problems yielded better results when compared to other algorithms. Chen et al. (1995) [12] proposed a GA for flow shop problems with makespan as the criterion. Compare the computational results of the heuristic with the results of some existing heuristics. The conclusions show that the GA based heuristic can always give the best results in a short time on a workstation. Chaudhry et al.(2011) [13] done Simultaneous scheduling of machines and automated guided vehicles in flexible manufacturing systems using genetic algorithms. Deroussi et al. (2008) [14] proposed a simple metaheuristic approach to the simultaneous scheduling of machines and automated guided vehicles.

\section{SIMULTANEOUS SCHEDULING PROBLEMS IN FMS}

\section{Problem Description}

A numerical example available in the literature proposed by Bilge and Ulusoy (1995) for simultaneous scheduling of machines and AGVs in FMS environment is considered in the present work which includes four layouts- ten jobsets process times and travel time data.Fig: 1 indicates the simultaneous scheduling of machines and Agv,s. 


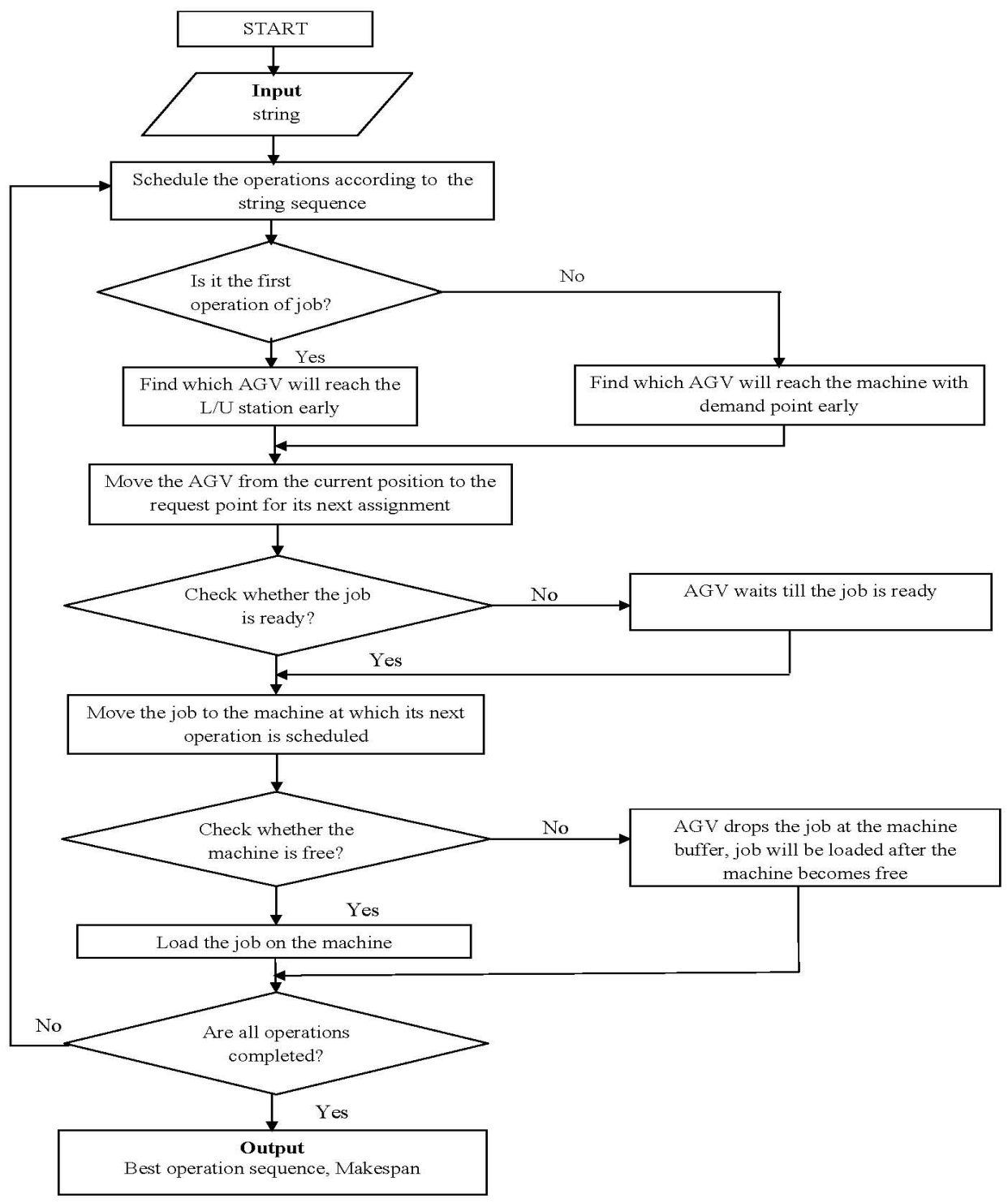

Figure 1: Flowchart for Simultaneous scheduling of machines and AGV,S

\section{Objective Function}

The main objective in the FMS scheduling problems is minimization of the operation completion time. The operation completion time is the sum of the processing time and the travel time.

i.e, Minimize $\mathrm{O}_{\mathrm{ij}}=\mathrm{T}_{\mathrm{ij}}+\mathrm{P}_{\mathrm{ij}}$

Where, $T_{i j}=$ Traveling time for $\mathrm{j}^{\text {th }}$ operation and $\mathrm{i}^{\text {th }}$ job

$\mathrm{P}_{\mathrm{ij}}=$ operation processing time

\section{Optimization Parameters Considered}

Population Size $=$ Double the no of operations

Iterations completed $=1000$ 


\section{Differential Evolution}

Differential Evolution (DE) Algorithm was developed by Storn and Price (1995). The main working principle behind the working of DE is the calculation of vector differences between randomly chosen population members.

The steps involved in DE are given below

Step 1: Generate Initial population randomly

Step 2: For each vector, to evaluate the desired optimization fitness function.

Step 3: The vector with the best makespan is then computed and is taken as the base vector for the next generation, $\mathrm{X}_{\mathrm{best}}$.

Step 4: Four vectors $\mathrm{X}_{1}, \mathrm{X}_{2}, \mathrm{X}_{3} \& \mathrm{X}_{4}$ will be randomly selected in the population is added to a best vector to get the resultant vector known as mutant vector $\left(\mathrm{X}_{\text {new }}\right)$, as given below

$X_{\text {new }}=X_{\text {best }}+F_{1}\left(X_{1}-X_{2}\right)+F_{2}\left(X_{3}-X_{4}\right)$

Where $F_{1}, F_{2}>0$ are scaling factor which controls, the magnitude of the differential variation

Step 5: Do the crossover operation for mutant vector

Step 6: Repeat the procedure until termination criterion reached

Figure 2: indicates the steps involved in DE Algorithm 


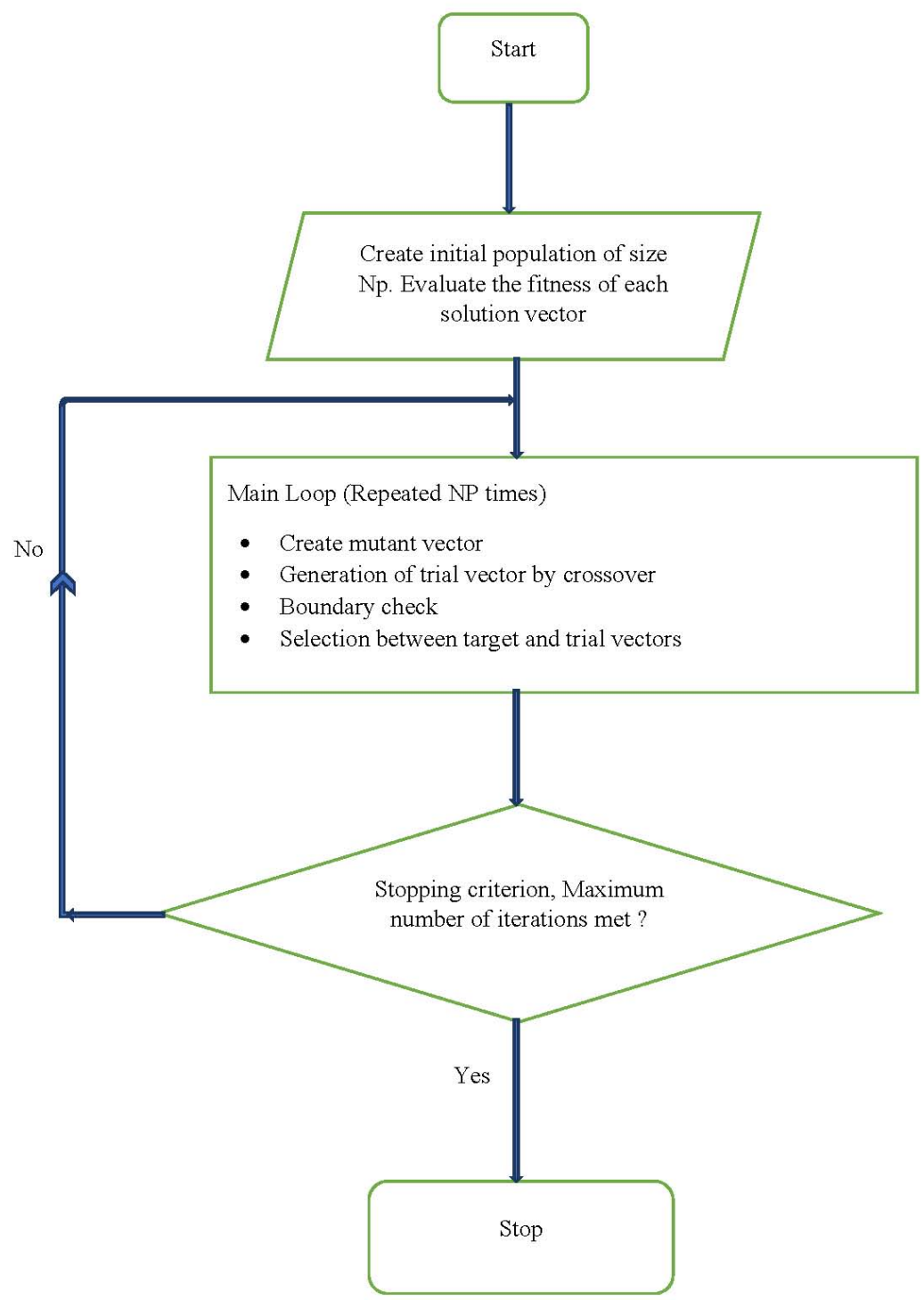

Figure 2: Fow chart for DE Algorithm

For implementation of DE, Job set 7 and Layout 3 are considered as an example. DE computes the vector differences between randomly chosen population members and receptor editing for different jobs and the sequences are obtained based on the mutation and crossover.

The DE is explained in the following steps for the job set 7 :

Step 1: Considering the job set

\begin{tabular}{|c|c|c|c|c|c|c|c|}
\hline \multicolumn{9}{|c|}{ Layout: 3 } & \multicolumn{2}{c|}{ No of jobs: 8 } & \multicolumn{3}{c|}{ No of operations: 19 } \\
\hline Job 1 & Job 2 & Job 3 & Job 4 & Job 5 & Job 6 & Job 7 & Job 8 \\
\hline M1-M4 & M2-M4 & M2-M4 & M3-M4 & M1-M3 & M2-M3-M4 & M1-M2-M3 & $\begin{array}{c}\text { M1-M2- } \\
\text { M4 }\end{array}$ \\
\hline $1-2$ & $3-4$ & $5-6$ & $7-8$ & $9-10$ & $11-12-13$ & $14-15-16$ & $\begin{array}{c}17-18- \\
19\end{array}$ \\
\hline
\end{tabular}


For the operations in a job set, numbers are assigned serially.

Step 2: Generating the Population size (double the number of operations) randomly by using precedence relation i.e., operation of the same job set must be in increasing order but anywhere in the sequence. These are presented in Table 1.3 and the steps discussed above in simultaneous scheduling of machines and AGV,s are implemented to identify the maximum operational completion time (makespan) for each sequence.

Table 1.3: Generated population size for the $D E$

\begin{tabular}{|c|c|c|}
\hline S.No & Sequence & Makespan \\
\hline 1 & $9-5-11-14-17-7-3-1-12-15-10-6-4-18-2-8-16-19-13$ & 110 \\
\hline 2 & 11-7-3-9-1-17-5-14-10-15-8-2-6-18-12-4-16-19-13 & 112 \\
\hline 3 & 17-7-5-9-3-1-11-14-2-4-12-8-6-10-18-15-19-16-13 & 116 \\
\hline 4 & 14-7-9-17-3-5-1-11-10-6-15-12-18-4-8-2-19-13-16 & 116 \\
\hline 5 & $7-1-17-5-11-14-3-9-18-6-15-2-12-4-10-8-16-19-13$ & 116 \\
\hline 6 & 17-9-14-7-11-5-3-1-8-15-18-10-4-12-2-6-16-13-19 & 119 \\
\hline 7 & 11-7-1-14-3-17-9-5-12-18-10-15-8-2-4-6-13-19-16 & 121 \\
\hline 8 & 14-3-5-9-7-11-1-17-2-10-6-8-18-4-15-12-19-13-16 & 121 \\
\hline 9 & 17-7-14-1-9-3-11-5-2-4-10-18-6-12-15-8-13-19-16 & 121 \\
\hline 10 & $3-17-14-7-1-5-9-11-6-2-15-12-10-4-8-18-13-19-16$ & 121 \\
\hline 11 & 14-11-17-5-7-3-9-1-10-4-2-12-6-15-8-18-19-16-13 & 123 \\
\hline 12 & $5-17-11-1-3-9-7-14-10-18-15-8-12-2-4-6-19-13-16$ & 123 \\
\hline 13 & $3-1-7-5-17-9-11-14-4-10-12-2-6-18-8-15-16-13-19$ & 124 \\
\hline 14 & $3-1-14-5-9-17-7-11-15-8-12-10-6-18-4-2-16-13-19$ & 125 \\
\hline 15 & 11-7-14-5-1-17-9-3-10-4-6-8-15-2-12-18-13-16-19 & 125 \\
\hline 16 & $11-7-3-1-9-14-17-5-15-2-12-8-4-6-18-10-13-16-19$ & 125 \\
\hline 17 & $9-14-7-5-17-3-11-1-8-15-12-6-4-18-2-10-16-13-19$ & 125 \\
\hline 18 & 5-1-14-3-9-7-17-11-15-8-10-18-2-6-4-12-16-19-13 & 126 \\
\hline 19 & 17-11-14-9-1-5-3-7-8-10-4-15-12-18-6-2-16-19-13 & 126 \\
\hline 20 & $11-1-17-5-9-7-14-3-8-4-18-15-12-2-10-6-16-19-13$ & 126 \\
\hline 21 & $3-7-11-5-14-9-1-17-6-8-10-15-12-4-18-2-13-16-19$ & 127 \\
\hline 22 & 11-14-5-1-9-7-17-3-2-4-15-8-12-6-10-18-19-16-13 & 127 \\
\hline 23 & $9-3-1-17-11-5-14-7-15-8-4-12-6-2-10-18-13-19-16$ & 127 \\
\hline 24 & 11-9-1-14-7-5-17-3-15-4-6-10-8-2-12-18-19-13-16 & 127 \\
\hline 25 & 11-17-5-9-3-1-14-7-8-15-12-6-4-2-10-18-16-13-19 & 127 \\
\hline 26 & 1-7-11-9-17-5-14-3-2-4-10-12-6-18-15-8-16-13-19 & 129 \\
\hline 27 & $9-17-3-11-14-1-5-7-10-4-18-8-15-6-12-2-16-13-19$ & 129 \\
\hline 28 & 11-17-9-1-14-7-5-3-18-15-6-10-2-8-4-12-19-16-13 & 130 \\
\hline 29 & 17-1-11-9-14-5-7-3-12-10-4-2-8-6-18-15-19-16-13 & 130 \\
\hline 30 & $9-7-11-5-1-3-17-14-6-8-18-4-15-10-2-12-19-16-13$ & 130 \\
\hline 31 & $11-5-7-1-3-9-17-14-8-4-6-18-2-10-15-12-19-13-16$ & 130 \\
\hline 32 & $5-1-9-14-11-3-7-17-6-18-2-10-4-12-15-8-16-19-13$ & 130 \\
\hline 33 & 11-5-1-7-14-9-3-17-6-8-15-18-10-12-2-4-19-16-13 & 130 \\
\hline 34 & 9-3-14-5-11-17-1-7-15-4-2-18-6-12-10-8-16-13-19 & 130 \\
\hline 35 & 11-3-9-1-14-17-7-5-8-4-6-15-18-12-2-10-16-19-13 & 130 \\
\hline 36 & $9-1-7-17-3-14-11-5-6-10-2-15-18-12-4-8-13-19-16$ & 134 \\
\hline 37 & 14-1-5-7-9-17-11-3-10-4-12-18-2-8-6-15-19-13-16 & 135 \\
\hline 38 & 5-14-9-7-17-1-11-3-12-2-4-8-18-15-10-6-19-13-16 & 138 \\
\hline
\end{tabular}

From the above table it can be interpreted that in $1^{\text {st }}$ sequence, number ' 9 ' represents $1^{\text {st }}$ operation on the job no 5 and similarly number ' 5 ' represents the $1^{\text {st }}$ operation on job no 3 . Similarly number ' 19 ' represents $3^{\text {rd }}$ operation on job no 8 and so on. 
Step 3: After all the sequences of the initial population have been evaluated, the best among them is taken. In this case the best in initial population is

$$
X_{\text {best }}=9-5-11-14-17-7-3-1-12-15-10-6-4-18-2-8-16-19-13 \text { with makespan } 110
$$

Step 4: Four vectors $\mathrm{X}_{1}, \mathrm{X}_{2}, \mathrm{X}_{3} \& \mathrm{X}_{4}$ will be randomly selected in the population is added to a best vector to get the resultant vector known as mutant vector $\left(\mathrm{X}_{\text {new }}\right)$, as $\mathrm{X}_{\text {new }}=\mathrm{X}_{\text {best }}+\mathrm{F}_{1}\left(\mathrm{X}_{1}-\mathrm{X}_{2}\right)+\mathrm{F}_{2}\left(\mathrm{X}_{3}-\mathrm{X}_{4}\right)$

$$
\begin{aligned}
& 9-5-11-14-17-7-3-1-12-15-10-6-4-18-2-8-16-19-13=X_{1} \\
& 11-7-3-9-1-17-5-14-10-15-8-2-6-18-12-4-16-19-13=X_{2} \\
& 17-7-5-9-3-1-11-14-2-4-12-8-6-10-18-15-19-16-13=X_{3} \\
& 14-7-9-17-3-5-1-11-10-6-15-12-18-4-8-2-19-13-16=X_{4}
\end{aligned}
$$

Subtracting and add these four vectors (absolute value is taken) and as suggested by Storn and Price [40] multiplying it with Factor $F 1=0.65$ and $F 2=0.85$ and rounding off, we get

$0.65\{(9-5-11-14-17-7-3-1-12-15-10-6-4-18-2-8-16-19-13)-(11-7-3-9-1-17-5-14-10-15-8-2-6-18-12-4-16-19-13)\}$

$+0.85\{(17-7-5-9-3-1-11-14-2-4-12-8-6-10-18-15-19-16-13)-(14-7-9-17-3-5-1-11-10-6-15-12-18-4-8-2-19-13-$

16)\}

$=0.65(2-2-8-5-16-10-2-13-2-0-2-4-2-0-10-4-0-0-0)+0.85\{(3-0-4-8-0-4-10-3-8-2-3-4-12-6-10-13-0-3-3)$

$=(1-1-5-3-10-7-1-8-1-0-1-3-1-0-7-3-0-0-0)+(3-0-3-7-0-3-9-3-7-2-3-3-10-5-9-11-0-3-3)$

$=4-1-8-10-10-10-10-11-8-2-4-6-11-5-16-14-0-3-3$

Adding this with the best vector

9-5-11-14-17-7-3-1-12-15-10-6-4-18-2-8-16-19-13

We get

13-6-19-24-27-17-13-12-20-17-14-12-15-23-18-22-16-22-16

Now converting the values above 19 (max value allowed to values within bounds) we get

13-6-19-5-8-17-13-12-1-17-14-12-15-4-18-3-16-3-16

Step 5: Do the crossover operation for mutant vector

Mutant vector crossed over randomly with another population member

9-3-14-5-11-17-1-7-15-4-2-18-6-12-10-8-16-13-19

Chromosomes before crossover:

\section{3-6-19-5- 8-17- 13-12-1-17-14-12-15- 4- 18- 3- 16- 3- 16}

9-3-14-5-11-17-1 - 7-15- 4- 2- 18- 6- 12-10- 8- 16-13-19

Chromosomes crossover

13-6-19-5- 8-17- 13-12-1-17 -2- 18- 6- 12-10- 8- 16-13-19 


\section{9-3-14-5-11-17-1 - 7-15- 4 -14 -12 -15 - 4 -18- 3- 16- 3- 16}

After crossover with crossover factor of 0.5 we get the resulting vector as

13-6-19-5- 8-17- 13-12-1-17 -2- 18- 6- 12-10- 8- 16-13-19

Here it is observed that this vector doesn't contain all the operations and some operations are repeated. Hence the corrected repair function is used to avoid repetition and also used to include all the operations. So the output of this function is

13-6-19-5- 8-17- 3-12-1- 4 -2- 18- 7- 9-10-11-16-14-15

\section{Repair Function:}

Repair function is used to make sure the vector so generated using random numbers follows precedence requirement constraints of the operations. If the precedence is not followed, the repair function swaps values within the array

$$
\text { 7-3-14-11- 5-17- 1-9-12-8 -18- 15- 4- 6-10- 2- 13-16-19 }
$$

Step 5: Receptor Editing:

A number of worst makespan value chromosomes are eliminated from the population after the cross over operation and randomly generated chromosomes are added in those places. After editing the chromosomes in the population the new population will be the input to the next iteration until termination criterion is reached.

Step 6: Termination Criterion

The process of selection, crossover, mutation and receptor editing are repeated till the termination criterion is satisfied.

A number of termination criteria are available in the literature like, repeating the procedure for number of generations, running the algorithm for a fixed duration of time, and stopping the simulation when there is no improvement in fitness for the last "g" generations.

In this work the first criterion viz., repeating the procedure for number of generations is taken as the termination criterion.

Step 9: The best sequence and its corresponding makespan arriving after 1000 iterations is presented in Table 1.4.

Table 1.4: Operations schedule through DE (for Problem set 7 and layout 3)

\begin{tabular}{|c|c|c|c|c|c|c|c|c|c|c|c|c|c|}
\hline $\begin{array}{c}\text { O.N } \\
0\end{array}$ & $\begin{array}{c}\text { M.N } \\
\mathbf{0}\end{array}$ & $\begin{array}{c}\text { V.N } \\
\text { o }\end{array}$ & $\begin{array}{l}\text { VP } \\
\mathbf{L}\end{array}$ & $\begin{array}{c}\text { POM } \\
\mathbf{N}\end{array}$ & $\begin{array}{c}\text { VR } \\
T\end{array}$ & $\begin{array}{c}\text { POC } \\
\mathbf{T}\end{array}$ & $\begin{array}{c}\text { VET }=\text { VRT }+\mathrm{TR} \\
\text { T1 } \\
\text { (4 to } 5)\end{array}$ & $\begin{array}{c}\operatorname{Max}(7, \\
8)\end{array}$ & $\begin{array}{c}\text { VLT }=\text { VET }+\mathrm{TR} \\
\mathrm{T} 2 \\
(5 \text { to } 2)\end{array}$ & $\underset{T}{\mathrm{MR}}$ & $\begin{array}{c}\operatorname{Max}(1 \\
0,11)\end{array}$ & $\begin{array}{l}\text { Proce } \\
\text { ss } \\
\text { Time }\end{array}$ & $\begin{array}{c}\text { Make } \\
\text { Span }\end{array}$ \\
\hline$(1)$ & (2) & (3) & (4) & $(5)$ & (6) & (7) & $(8)$ & (9) & $(10)$ & $(11)$ & (12) & $(13)$ & (14) \\
\hline 7 & 3 & 1 & 0 & 0 & 0 & 0 & 0 & 0 & 10 & 0 & 10 & 16 & 26 \\
\hline 3 & 2 & 2 & 0 & 0 & 0 & 0 & 0 & 0 & 4 & 0 & 4 & 11 & 15 \\
\hline 14 & 1 & 1 & 3 & 0 & 10 & 0 & 14 & 14 & 16 & 0 & 16 & 10 & 26 \\
\hline 11 & 2 & 2 & 2 & 0 & 4 & 0 & 14 & 14 & 18 & 15 & 18 & 13 & 31 \\
\hline 5 & 2 & 1 & 1 & 0 & 16 & 0 & 28 & 28 & 32 & 31 & 32 & 9 & 41 \\
\hline 17 & 1 & 2 & 2 & 0 & 18 & 0 & 28 & 28 & 30 & 26 & 30 & 11 & 41 \\
\hline 1 & 1 & 1 & 2 & 0 & 32 & 0 & 42 & 42 & 44 & 41 & 44 & 6 & 50 \\
\hline 9 & 1 & 2 & 1 & 0 & 30 & 0 & 42 & 42 & 44 & 50 & 50 & 9 & 59 \\
\hline 12 & 3 & 1 & 1 & 2 & 44 & 31 & 46 & 46 & 52 & 26 & 52 & 19 & 71 \\
\hline 8 & 4 & 1 & 3 & 3 & 52 & 26 & 52 & 52 & 54 & 0 & 54 & 7 & 61 \\
\hline 18 & 2 & 2 & 1 & 1 & 44 & 41 & 44 & 44 & 46 & 41 & 46 & 9 & 55 \\
\hline 15 & 2 & 1 & 4 & 1 & 54 & 26 & 58 & 58 & 60 & 55 & 60 & 9 & 69 \\
\hline 4 & 4 & 2 & 2 & 2 & 46 & 15 & 46 & 46 & 54 & 61 & 61 & 9 & 70 \\
\hline 6 & 4 & 1 & 2 & 2 & 60 & 41 & 60 & 60 & 68 & 70 & 70 & 7 & 77 \\
\hline
\end{tabular}




\begin{tabular}{|c|c|c|c|c|c|c|c|c|c|c|c|c|c|}
\hline 10 & 3 & 2 & 4 & 1 & 54 & 59 & 58 & 59 & 67 & 71 & 71 & 18 & 89 \\
\hline 2 & 4 & 1 & 4 & 1 & 68 & 50 & 72 & 72 & 82 & 77 & 82 & 6 & 88 \\
\hline 13 & 4 & 2 & 3 & 3 & 67 & 71 & 67 & 71 & 73 & 88 & 88 & 6 & 94 \\
\hline 16 & 3 & 2 & 4 & 2 & 73 & 69 & 79 & 79 & 85 & 89 & 89 & 13 & 102 \\
\hline 19 & 4 & 1 & 4 & 2 & 82 & 55 & 88 & 88 & 96 & 94 & 96 & 8 & 104 \\
\hline
\end{tabular}

Table 1.4 shows operation scheduling of through Differential Evolution Algorithm for job set 7 layout 3. From the table it is observed that operation 7 on machine 3 is completed by 26 minutes, hence $3^{\text {rd }}$ operation will start after completion of $7^{\text {th }}$ operation on machine 3 . In case of job set 7 and layout 3 operation 14 on machine 1 is completed by 26 minutes hence $14^{\text {th }}$ operation on machine 1 will start after completion of $3^{\text {rd }}$ operation on machine 2 . Similarly no operation on the particular machine will start until the operation on the machine is completed.

From the simultaneous scheduling procedure for first two operations AGVs are selected randomly in case of third operation $\mathrm{AGV}$ ' 1 ' is selected basing on the availability of $\mathrm{AGV}$ with minimum travel time this constraint will be taking care in the procedure. For job set 7 and layout 3 the operational completion time (makespan) is 104 minutes.

The makespan values of different algorithms available in the literature and the comparision with the proposed algorithm for $\mathrm{t} / \mathrm{p}>0.25$ are done and presented in Table 1.5.

Table 1.5: Comparison of make span values (for $t / p>0.25$ )

\begin{tabular}{|c|c|c|c|c|c|c|c|}
\hline JOB.No & STW & UGA & AGA & RGA & DGTHA & IACGA & $\mathrm{DE}$ \\
\hline 1.1 & 96 & 96 & 96 & 96 & 96 & 96 & 96 \\
\hline 2.1 & 105 & 104 & 102 & 100 & 100 & 100 & 98 \\
\hline 3.1 & 105 & 105 & 99 & 99 & 99 & 99 & 109 \\
\hline 4.1 & 118 & 116 & 112 & 112 & 112 & 112 & 116 \\
\hline 5.1 & 89 & 87 & 87 & 87 & 87 & 87 & 89 \\
\hline 6.1 & 120 & 121 & 118 & 118 & 118 & 118 & 116 \\
\hline 7.1 & 119 & 118 & 115 & 111 & 111 & 115 & 133 \\
\hline 8.1 & 161 & 152 & 161 & 161 & 161 & 161 & 150 \\
\hline 9.1 & 120 & 117 & 118 & 116 & 116 & 116 & 116 \\
\hline 10.1 & 153 & 150 & 147 & 147 & 147 & 150 & 167 \\
\hline 1.2 & 82 & 82 & 82 & 82 & 82 & 82 & 82 \\
\hline 2.2 & 80 & 76 & 76 & 76 & 76 & 76 & 76 \\
\hline 3.2 & 88 & 85 & 85 & 85 & 85 & 85 & 83 \\
\hline 4.2 & 93 & 88 & 88 & 87 & 87 & 88 & 90 \\
\hline 5.2 & 69 & 69 & 69 & 69 & 69 & 69 & 73 \\
\hline 6.2 & 100 & 98 & 98 & 98 & 98 & 98 & 90 \\
\hline 7.2 & 90 & 85 & 79 & 79 & 79 & 81 & 85 \\
\hline 8.2 & 151 & 142 & 151 & 151 & 151 & 151 & 131 \\
\hline 9.2 & 104 & 102 & 104 & 102 & 102 & 102 & 104 \\
\hline 10.2 & 139 & 137 & 136 & 135 & 135 & 141 & 149 \\
\hline 1.3 & 84 & 84 & 84 & 84 & 84 & 84 & 84 \\
\hline 2.3 & 86 & 86 & 86 & 86 & 86 & 86 & 82 \\
\hline 3.3 & 86 & 86 & 86 & 86 & 86 & 86 & 86 \\
\hline 4.3 & 95 & 91 & 89 & 89 & 89 & 89 & 96 \\
\hline 5.3 & 76 & 75 & 74 & 74 & 74 & 74 & 76 \\
\hline 6.3 & 104 & 104 & 104 & 103 & 103 & 104 & 92 \\
\hline 7.3 & 91 & 88 & 86 & 83 & 86 & 90 & 104 \\
\hline 8.3 & 153 & 143 & 153 & 153 & 153 & 153 & 133 \\
\hline 9.3 & 110 & 105 & 106 & 105 & 105 & 105 & 105 \\
\hline 10.3 & 143 & 143 & 141 & 139 & 138 & 140 & 129 \\
\hline 1.4 & 108 & 103 & 103 & 103 & 103 & 103 & 104 \\
\hline 2.4 & 116 & 113 & 108 & 108 & 108 & 108 & 112 \\
\hline 3.4 & 116 & 113 & 111 & 111 & 111 & 111 & 113 \\
\hline 4.4 & 126 & 126 & 126 & 126 & 121 & 126 & 128 \\
\hline 5.4 & 99 & 97 & 96 & 96 & 96 & 96 & 97 \\
\hline 6.4 & 120 & 123 & 120 & 120 & 120 & 122 & 119 \\
\hline 7.4 & 136 & 128 & 127 & 126 & 126 & 130 & 135 \\
\hline
\end{tabular}




\begin{tabular}{|c|c|c|c|c|c|c|c|}
\hline 8.4 & 163 & 163 & 163 & 163 & 163 & 163 & 152 \\
\hline 9.4 & 125 & 123 & 122 & 122 & 120 & 120 & 125 \\
\hline 10.4 & 171 & 164 & 159 & 158 & 159 & 159 & 161 \\
\hline
\end{tabular}

NOTE: STW - Bilge et al.(1995) UGA- Ulusoy et al.(1997)

AGA - Abdelmaguid et al.(2004) RGA- Reddy et al.(2006)

DGTHA - Deroussi et al.(2008) IACGA - I A Chaudhry et al.(2011)

DE - Differential Evolution

The optimal sequence of machines and AGVs and their corresponding makespans determined by using STW, UGA, AGA, RGA, DGTHA (2008), IACGA(2011), DE for t/p > 0.25 are shown in Table 1.5. From Table 1.5,out of 40 problems 5 problems gives improved results using STW in comparison with others, 10 problems gives improved results using UGA in comparison with others, 17 problems gives improved results using AGA in comparison with others, 25 problems gives improved results using RGA in comparison with others, 23 problems gives improved results using DGTHA in comparison with others, 19 problems gives improved results using IACGA in comparison with others, 19 problems gives improved results using DE in comparison with others. The makespan values of different algorithms available in the literature and the comparision with the proposed algorithm for $\mathrm{t} / \mathrm{p}<0.25$ are done and presented in Table 1.6.

Table 1.6: Comparison of make span values (for $\mathbf{t} / \mathbf{p}<\mathbf{0 . 2 5})$

\begin{tabular}{|c|c|c|c|c|c|c|c|}
\hline JOB.NO & STW & UGA & AGA & RGA & DGTHA & IACGA & DE \\
\hline 1.10 & 126 & 126 & 126 & 126 & 126 & 126 & 126 \\
\hline 2.10 & 148 & 148 & 148 & 148 & 148 & 148 & 131 \\
\hline 3.10 & 150 & 148 & 150 & 150 & 150 & 150 & 143 \\
\hline 4.10 & 121 & 119 & 119 & 119 & 119 & 119 & 123 \\
\hline 5.10 & 102 & 102 & 102 & 102 & 102 & 102 & 102 \\
\hline 6.10 & 186 & 186 & 186 & 186 & 186 & 186 & 146 \\
\hline 7.10 & 137 & 137 & 137 & 137 & 137 & 137 & 137 \\
\hline 8.10 & 292 & 271 & 292 & 292 & 292 & 292 & 247 \\
\hline 9.10 & 176 & 176 & 176 & 176 & 176 & 176 & 182 \\
\hline 10.10 & 238 & 236 & 238 & 238 & 238 & 238 & 218 \\
\hline 1.20 & 123 & 123 & 123 & 123 & 123 & 123 & 123 \\
\hline 2.20 & 143 & 143 & 143 & 143 & 143 & 143 & 128 \\
\hline 3.20 & 148 & 145 & 145 & 145 & 145 & 145 & 139 \\
\hline 4.20 & 116 & 114 & 114 & 114 & 114 & 114 & 116 \\
\hline 5.20 & 100 & 100 & 100 & 100 & 100 & 100 & 100 \\
\hline 6.20 & 183 & 181 & 181 & 181 & 181 & 181 & 141 \\
\hline 7.20 & 136 & 136 & 136 & 136 & 136 & 136 & 136 \\
\hline 8.20 & 287 & 268 & 287 & 287 & 287 & 287 & 244 \\
\hline 9.20 & 174 & 173 & 173 & 173 & 173 & 173 & 179 \\
\hline 10.20 & 236 & 238 & 236 & 236 & 236 & 236 & 212 \\
\hline 1.30 & 122 & 122 & 122 & 122 & 122 & 122 & 122 \\
\hline 2.30 & 146 & 146 & 146 & 146 & 146 & 146 & 129 \\
\hline 3.30 & 149 & 146 & 146 & 146 & 146 & 146 & 138 \\
\hline 4.30 & 116 & 114 & 114 & 114 & 114 & 114 & 117 \\
\hline
\end{tabular}




\begin{tabular}{|c|c|c|c|c|c|c|c|}
\hline 5.30 & 99 & 99 & 99 & 99 & 99 & 99 & 99 \\
\hline 6.30 & 184 & 182 & 182 & 182 & 182 & 182 & 141 \\
\hline 7.30 & 137 & 137 & 137 & 137 & 137 & 137 & 137 \\
\hline 8.30 & 288 & 270 & 288 & 288 & 288 & 288 & 245 \\
\hline 9.30 & 176 & 174 & 174 & 174 & 174 & 174 & 180 \\
\hline 10.30 & 237 & 241 & 237 & 237 & 241 & 237 & 191 \\
\hline 1.40 & 124 & 124 & 124 & 124 & 124 & 124 & 124 \\
\hline 2.41 & 217 & 217 & 217 & 217 & 217 & 217 & 191 \\
\hline 3.40 & 151 & 151 & 151 & 151 & 151 & 151 & 143 \\
\hline 3.41 & 222 & 221 & 221 & 221 & 221 & 221 & 209 \\
\hline 4.41 & 179 & 172 & 172 & 172 & 179 & 172 & 177 \\
\hline 5.41 & 154 & 148 & 148 & 148 & 148 & 148 & 148 \\
\hline 6.40 & 185 & 184 & 184 & 184 & 184 & 184 & 152 \\
\hline 7.40 & 138 & 137 & 137 & 137 & 137 & 137 & 137 \\
\hline 7.41 & 203 & 203 & 203 & 203 & 203 & 203 & 203 \\
\hline 8.40 & 293 & 273 & 293 & 293 & 293 & 293 & 248 \\
\hline 9.40 & 177 & 175 & 175 & 175 & 175 & 175 & 182 \\
\hline 10.40 & 240 & 244 & 240 & 240 & 240 & 240 & 220 \\
\hline
\end{tabular}

The optimal sequence of machines and AGVs and their corresponding makespans determined by using STW, UGA, AGA, RGA, DGTHA, IACGA, DE for t/p <0.25 are shown in Table 1.6. From Table 1.6, out of 42 problems 12 problems gives improved results using STW in comparison with others, 21 problems gives improved results using UGA in comparison with others, 21 problems gives improved results using AGA in comparison with others, 21 problems gives improved results using RGA in comparison with others, 20 problems gives improved results using DGTHA in comparison with others, 21 problems gives improved results using IACGA in comparison with others, 34 problems gives improved results using DE in comparison with others.

\section{RESULTS AND DISCUSSIONS}

Performance of the proposed Metaheuristic Algorithm is evaluated by considering 82 benchmark problems consisting of different job sets and layout configurations. These results are compared with the results obtained by different algorithms available in the literature. It was observed that DE outperformed STW in 50 problems, UGA in 37 problems, AGA in 36 problems, RGA in 34 problems, DGTHA in 35 problems and IACGA in 34 problems. Where as its performance is on par with those algorithms in the remaining problems.

\section{CONCLUSIONS}

In this paper a metaheuristic Differential evolution algorithm is implemented for simultaneous scheduling of machines and two AGVs in a FMS, which minimizes the makespan, completes the jobs faster, and saves resources. Out of 82 problems DE outperformed in 53 problems when compared with others. The purpose of this work is to make AGV scheduling an integral part of the scheduling activity, actively participating in the specification of the off-line schedule, rather than just reacting to it. The iterative algorithm created anticipates the complete set of flow requirements for a given machine schedule and makes vehicle assignments accordingly. 


\section{REFERENCES}

1. Akturk, MS, Yilmaz, H, "Scheduling of automated guided vehicles in a decision making hierarchy", International Journal of Production Research 1996; 32: 577-591.

2. Sabuncuoglu, I, Hommertzheim, DL, "Experimental investigation of FMS machine and AGVscheduling rules against the mean flow time criterion”, International journal of production research 1992; 30(7): 1617-1635.

3. Karabtik, S, Sabuncuolu, I, “A beam search based algorithm for scheduling machines and AGVs in an FMS”, In: Proceedings of the Second Industrial EngineeringResearchConf, Los Angeles 1993; 308-312.

4. Kusiaka, "Material Handling in Flexible Manufacturing Systems. Material Flow”, 1985; 290- 295.

5. El-Maraghy, El, H.A., Ravi, T, “Modern tools for the design, modeling and evaluation of flexible manufacturing systems”,Int J Robot ComputIntegrManuf, 1992; 9(4): 335-340.

6. Lee, SM, Jung, HJ, “A multi-objective production planning model in a flexible manufacturing environment”, International journal of production research 1989; 27(11): 1981-1992.

7. Blazewicz, J., Eiselt, HA., Finke, G., Laporte, G., \&Weglarz, J. (1991). Scheduling tasks and vehicles in a flexible manufacturing system, Int J Flex ManufSyst, 4, 5-16.

8. Bilge, U, Ulusoy, G, "A time window approach to simultaneous scheduling of machines and material handling system in an FMS”,. Operations Research 1995; 43(6):1058-1070.

9. Ulusoy, G., Srvnkaya, F-Serifogulg. And Umit Bilge, 1997, “A Genetic algorithm approach to the simultaneous scheduling of machines and automated guided vehicles," Computers \& Operations Research, Vol.24, pp. 335-351.

10. Abdelmaguid, T. F., Nasef, A. O., Kamal, B. A. and Hassan, M. F., 2004, "A hybrid GA / heuristic approach to the simultaneous scheduling of machines and automated guided vehicles, " International Journal of Production Research, Vol.42, pp. 267-281.

11. Reddy, B. S. P. and Rao, C. S. P., 2006, “A hybrid multi-objective GA for simultaneous scheduling of machines and AGVs in FMS, " International Journal of Advanced Manufacturing Technology, Vol.31, pp. 602-613.

12. Chen, C. L., Vempati, V. S. and Aljaber, N., 1995, "Theory and methodology an application of Genetic algorithms for flow shop problems, " European Journal of Operations Research, Vol. 80, pp. 389-396.

13. Chaudhry, I. A., Mahmoud, S. and Shami, M., 2011, "Simultaneous scheduling of machines and automated guided vehicles in flexible manufacturing systems using genetic algorithms," J.Cent. South Univ. Technol, Vol.18, pp. 1473-1486.

14. Deroussi, L., Gourgand, M. and Tchernev, N., 2008, “A simple metaheuristic approach to the simultaneous scheduling of machines and automated guided vehicles," International Journal of Production Research, Vol. 46, pp. 2143-2164. 